\title{
Antibacterial Activity of Chitosan and the Interpolyelectrolyte Complexes of Poly(acrylic acid)- Chitosan
}

\author{
Hortensia Ortega-Ortiz ${ }^{1 *}$ Baltazar Gutiérrez-Rodríguez $^{2}$, Gregorio Cadenas-Pliego $^{1}$ and \\ Luis Ibarra Jimenez ${ }^{1}$ \\ ${ }^{1}$ Centro de Investigación en Química Aplicada; Blvd. E. Reyna, 140; Col. Saltillo 400; CP 25253; Saltillo - México. \\ ${ }^{2}$ Facultad de Ciencias Químicas; UAdeC; Blvd. V. Carranza; Col. Republica Ote.; C.P.: 25000; Saltillo - México
}

\begin{abstract}
The antimicrobial activity of chitosan and water soluble interpolyelectrolyte complexes of poly(acrylic acid)chitosan was studied. Chitosans of two different molecular weights were tested at different concentration for 0.5 to 5 $g \cdot L^{-1}$ as antimicrobial agents against $P$. aeruginosa and $P$. oleovorans. In both cases, the best microbial inhibition was obtained with the concentration of $5 \mathrm{~g} \cdot \mathrm{L}^{-1}$. However, the interpolyelectrolyte complexes of poly(acrylic acid)chitosan with composition $\varphi=2$ produced higher antibacterial activity than the two chitosans at the concentration of $0.5 \mathrm{~g} \cdot \mathrm{L}^{-1}$. The NPEC2 complex was more effective than chitosans. This could be attributed to the number of moles of the amino groups of chitosan and the carboxylic acid groups of the interpolyelectrolyte complexes poly(acrylic acid).
\end{abstract}

Key words: antibacterial activity, chitosan, complexes, poly(acrylic acid), polyelectrolytes

\section{INTRODUCTION}

Chitosan is polyglucosamine, polycationic, nontoxic and biodegradable. The presence of free amino groups helps in biological activities. One of these is the antimicrobial activity.

Pseudomonas aeruginosa is a Gram-negative bacteria with polar flagella pertaining to the branch of the proteobacteria (Pace, 1997; Hardalo, 1997). An opportunistic human pathogen, it is also an opportunistic pathogen of plants.

$P$. oleovorans are widely distributed in nature (Costerton, 1980) and have been isolated from soils, contaminated waters, as well as from plants and animals. These organisms are potentially pathogens for human and some can also infect plants such as Arabidopsis thaliana (Rahme et al.
1997), invertebrates such as Caenorhabditis elegans (Tan et al. 2000) and insects such as Drosophila melanogaster (D'Argenio et al. 2002). The antifungicidal activity of chitosan (Hirano, 1989) and its capacity to promote metabolic changes in plants by inducing the accumulation of phytoalexins and other phenolic compounds with antimicrobial activity aid in the growth of plants. Chitosan has been demonstrated to induce an increase in germination percentage and yield of cereal plants and tomato (Hadwiger, 1984; Hidalgo et al. 1989).

Omura et al. (2002) measured the antimicrobial activity (Minimum Inhibitory Concentration, MIC) of chitosan and chitooligosaccharides with different molecular weights but without acetylated groups. They observed that chitosan with high

*Author for correspondence: hortega@ciqa.mx 
molecular weight showed strong antimicrobial activity against Gram positive bacteria, whereas chitosans of $11 \mathrm{kDa}$ and $20-30 \mathrm{kDa}$ molecular weight were most effective against Gram negative bacteria.

Chung et al. (2003) recently reported that the antibacterial activity of chitosan against Escherichia coli and S. aureus increased with ionic force and at a pH less than 6.0, but decreased with the addition of metal ion. Additionally, they observed that the antibacterial activity of chitosan increased against Escherichia coli in the presence of EDTA, but there was no significant change against $S$. aureus. The antibacterial activity of chitosan was also found to be dependent on its charges and solubility.

The interpolyelectrolyte complexes are the products of reactions between electrostatic complementary chains. It is known that water soluble non-stoichiometric interpolyelectrolyte complexes (NPEC) can be obtained from oppositely charged polyelectrolytes of various chemical structures. NPEC contain charged groups in a non-equivalent ratio $(\varphi=[+] /[-] \neq 1)$ and are soluble in aqueous media (Kabanov, et al. 1984).

Ortega Ortiz, et al. (2003) treated tomato seeds (Lycopersicon esculentum Mill. var. Floradade) with $0.1 \%(\mathrm{v} / \mathrm{v})$ of interpolyelectrolyte complexes of poly(acrylic acid)-chitosan in water with $5 \mathrm{~g} \cdot \mathrm{L}^{-1}$ of $\mathrm{NaCl}$ and demonstrated a resulting higher resistance of the tomato seedlings against attack by Fusarium oxysporum and Phytophthora capsici (Ortega-Ortiz et al. 2003).

In this work the antimicrobial activity of chitosan and non-stoichiometric interpolyelectrolyte complexes of poly(acrylic acid)-chitosan was evaluated against two species of Pseudomonas.

\section{MATERIALS AND METHODS}

\section{Materials}

Chitosan (CS) was supplied by Aldrich. The intrinsic viscosity $(\eta)$ of both high and low molecular weight chitosans were determined using a solution of $0.2 \quad \mathrm{M} \quad \mathrm{CH}_{3} \mathrm{COONa} / 0.3 \quad \mathrm{M}$ $\mathrm{CH}_{3} \mathrm{COOH}$ at $30^{\circ} \mathrm{C}$. The molecular weight of chitosans were determined according the MarkHouwink equation: $[\eta]=\mathrm{K} \cdot \mathrm{M}^{\alpha}$ where $\mathrm{K}=7.6 \times 10^{-2}$ and $\alpha=0.76$ (Rinaudo, et al. 1993). The molecular weight was $3.5 \times 10^{5}$ for the high molecular weight chitosan $\left(\mathrm{CS}_{\mathrm{H}}\right)$ and $6.5 \times 10^{4}$ for the low molecular weight chitosan $\left(\mathrm{CS}_{\mathrm{L}}\right)$. The deacetylation degree was determined by FTIR (Brugnerotto et al. 2001), which was $83 \%$ and $88 \%$ for the chitosans of high and low molecular weights, respectively. Different concentrations of chitosan solutions $\left(0.5\right.$ to $\left.5 \mathrm{~g} \cdot \mathrm{L}^{-1}\right)$ were prepared in acetate buffer at $\mathrm{pH} 4.5$.

The synthesis of the poly(acrylic acid) (PAA) was done as described by Ortega-Ortiz et al. (2003). The two molecular weights of the PAA were determined by the viscosity in dioxan at $30^{\circ} \mathrm{C}$ (Brandrup and Immergut, 1989) and found to be $1 \times 10^{5}$ for PAA100 and $2 \times 10^{5}$ for PAA200. Further characterization was done by infrared spectroscopy and calorimetric methods.

Water soluble non-stoichiometric interpolyelectrolyte complexes (NPEC) were prepared by polyanions of PAA100 (NPEC1) or PAA200 (NPEC2), and the molecular weight of polycation chitosan was the same at 65,000 for both cases. The composition of NPEC1 and the NPEC2 was calculated according to the equation: $\varphi=[\mathrm{CS}] /[\mathrm{PAA}]=2$. The complexes were first prepared by mixing of corresponding quantities of $0.02 \mathrm{M}$ PAA and $0.02 \mathrm{M}$ chitosan and then adjusting the $\mathrm{pH}$ to 4.5 with acetate buffer. Previous reports substantiated that composition of $\varphi \neq 1$ resulted in the possibility of obtaining soluble complexes with other polyelectrolytes (Kabanov, et al. 1984). For this reason and for the sake of exploration, this composition was tested.

The microorganisms used were Pseudomonas aeruginosa (ATCC 13388) and Pseudomonas oleovorans (ATCC 29347). The strains were grown in nutrient agar and peptone-agar medium at $37^{\circ} \mathrm{C}$ and $30^{\circ} \mathrm{C}$, respectively. For both strains, a concentration of $10^{9}$ cells $/ \mathrm{mL}$ was used in all the antimicrobial assays.

\section{Methods}

The complex NPEC and PAA were dried at $60^{\circ} \mathrm{C}$ for $12 \mathrm{~h}$, while chitosan was dried under vacuum. The infrared spectra of polyelectrolytes and NPEC were obtained using an Fourier Transform Infrared spectrophotometer Nicolet Magna 500. The samples were prepared in $\mathrm{KBr}$ pellets (thickness < $0.2 \mathrm{~mm}$ ) and maintained in desiccated condition before taking the spectra.

The culture media and the chitosan solutions were sterilized in an autoclave (Tuttnauer BRINKMANN 2540E) at $121^{\circ} \mathrm{C}$ for 15 minutes. The complexes were sterilized with a UV lamp (Cole-Parmer 9815) at $275 \mathrm{~nm}$ for 30 minutes to avoid intercrossing. The antimicrobial activity was 
evaluated by inoculating $P$. oleovorans in peptone broth $\left(30^{\circ} \mathrm{C}\right)$ and $P$. aeruginosa in nutrient broth $\left(37^{\circ} \mathrm{C}\right)$, followed by the addition of each one of the chitosans in the range of 0.5 to $5.0 \mathrm{~g} \cdot \mathrm{L}^{-1}$ concentrations. The flasks were then immediately incubated in a rotary shaker $(150 \mathrm{rpm})$ at an optimum temperature for $24 \mathrm{~h}$. Samples were withdrawn at every $3 \mathrm{~h}$ interval to check for bacterial growth. Three replications were maintained for every treatment of this study.

The inhibition percentage (\%) was evaluated by comparing cell numbers between the tests and control sets after $24 \mathrm{~h}$ of incubation.

The growth of bacterial strains was measured by determining the total proteins using Peterson method at $750 \mathrm{~nm}$ (Peterson, 1977) and by determining the reducing sugar formation using Somogyi-Nelson method at $610 \mathrm{~nm}$ (Nelson, 1944; Somogyi, 1952) in a UV-VIS spectrophotometer (SHIMADZU; Model UV-2401PC).

\section{RESULTS AND DISCUSSION}

The molecular weight of chitosans was determined using a solution of $0.3 \mathrm{M} \mathrm{CH}_{3} \mathrm{COOH} / 0.2 \mathrm{M}$ $\mathrm{CH}_{3} \mathrm{COONa}$ and after autoclaving for 15 minutes at $121^{\circ} \mathrm{C}$. They were prepared in buffer for determining the molecular weight because a greater stability of chitosans in acetate buffer was observed than in dilute acid solutions. The results showed that the molecular weight of the $\mathrm{CS}_{\mathrm{L}}$ using the buffer solution only decreased by $31 \%$, whereas the decrease was $79 \%$ for $\mathrm{CS}_{\mathrm{H}}$. The percent reduction was calculated following the method reported by Shin et al. (2001). Conversely, Choi and coworkers (1999) reported a 91\% decrease in the molecular weight of $1 \%$ chitosan (molecular weight $1.1 \times 10^{6}$ ) in acetic acid after autoclaving for 15 minutes at $121^{\circ} \mathrm{C}$.

The infrared spectra of chitosan, PAA and complex (PAA-CS) are shown in Figure 1 for comparative purposes.

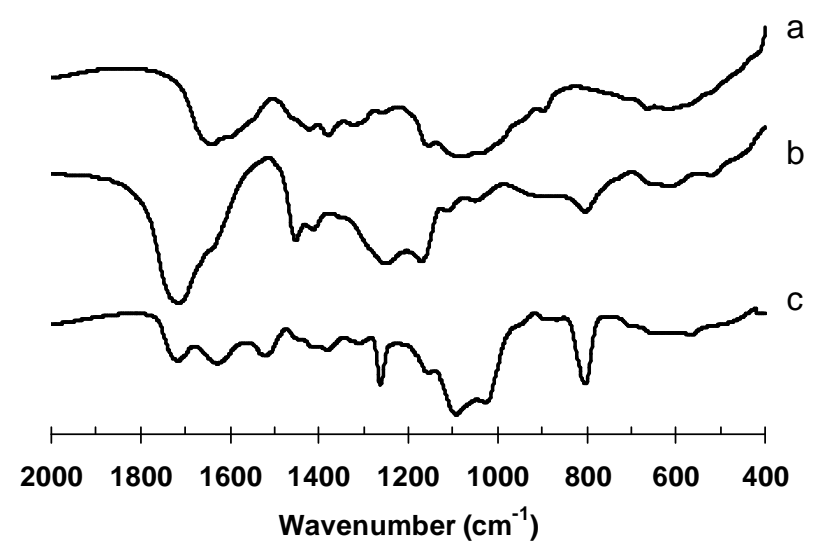

Figure 1 - FTIR spectra of chitosan (a), polyacrylic acid (b) and nonstoichiometric interpolyelectrolyte complex of poly(acrylic acid) and chitosan (c), $\varphi=2$.

Chitosan FTIR produced (Fig. 1a) characteristic bands at $1589 \mathrm{~cm}^{-1}$ corresponding to amino groups, and at $1650 \mathrm{~cm}^{-1}$ and $1340 \mathrm{~cm}^{-1}$ to amide I and amide II, respectively. The FTIR spectrum of PAA (Fig. 1b) (Kang et al. 1992) showed a strong band at $1730 \mathrm{~cm}^{-1}$ corresponding to the vibration stretching of carboxylic acid groups $(v s, \mathrm{C}=\mathrm{O})$.

The appearance of new peaks in the FTIR spectrum of the complex (PAA-CS) (Fig. 1c) at
$1640 \mathrm{~cm}^{-1}$ was attributed to the formation of $\mathrm{NH}_{3}{ }^{+}$ groups (Kang, et al. 1993) and the two strong peaks at $1530 \mathrm{~cm}^{-1}$ and $1410 \mathrm{~cm}^{-1}$ were due to the symmetric and asymmetric stretching of $\mathrm{COO}^{-}$ groups, respectively. These data confirmed the dissociation of carboxylic groups of PAA to $\mathrm{COO}^{-}$ groups which then reacted with protonated amino groups from CS through electrostatic interaction during the formation of the NPEC. 


\section{Antimicrobial activity of chitosan}

Chitosans $\mathrm{CS}_{\mathrm{H}}$ and $\mathrm{CS}_{\mathrm{L}}$ were evaluated at concentrations of 0.5 to $5 \mathrm{~g} \cdot \mathrm{L}^{-1}$ on $P$. aeruginosa and $P$. oleovorans. Although $P$. aeruginosa was inhibited by both low and high molecular weight chitosans (Table 1), the low molecular weight chitosan $\left(\mathrm{CS}_{\mathrm{L}}\right)$ recorded the highest antimicrobial activity $(72.52 \%)$ at concentration of $5 \mathrm{~g} \cdot \mathrm{L}^{-1}$.

Table 1 - The inhibition percentage (\%) of chitosans $\mathrm{CS}_{\mathrm{L}}$ and $\mathrm{CS}_{\mathrm{H}}$ against $P$. aeruginosa and P. oleovorans after 24 $\mathrm{h}$ of incubation.

\begin{tabular}{ccccc}
\hline \multirow{2}{*}{ Concentration $\boldsymbol{g} \cdot \boldsymbol{L}^{-\boldsymbol{I}}$} & \multicolumn{2}{c}{ P. aeruginosa } & \multicolumn{2}{c}{ P. oleovorans } \\
\cline { 2 - 5 } & $\boldsymbol{C} \boldsymbol{S}_{\boldsymbol{L}}$ & $\boldsymbol{C S}_{\boldsymbol{H}}$ & $\boldsymbol{C \boldsymbol { S } _ { \boldsymbol { L } }}$ & $\boldsymbol{C S}_{\boldsymbol{H}}$ \\
\hline 0.5 & 21.82 & 21.75 & 18.04 & 17.99 \\
1.0 & 26.84 & 26.21 & 22.06 & 21.21 \\
2.0 & 33.12 & 30.57 & 23.23 & 22.72 \\
3.0 & 52.87 & 37.58 & 55.05 & 57.07 \\
4.0 & 63.48 & 42.24 & 62.62 & 64.14 \\
5.0 & 72.52 & 64.57 & 68.69 & 71.07 \\
\hline
\end{tabular}

Choi et al. (1999) reported a $27 \%$ inhibition of $P$. aeruginosa at the same chitosan concentration with a molecular weight of 51,000. Shin and coworkers (2001) reported that the $P$. aeruginosa was not inhibited by smaller concentrations (up to $1 \%$ ) of chitosans of different molecular weights 1,800, 100,000 and 210,000. However, $P$. aeruginosa was inhibited by $72.52 \%$ with chitosan having a molecular weight of 65,000 and by $64.57 \%$ with high molecular weight chitosan $(325,000)$ at the $0.5 \%\left(5 \mathrm{~g} \cdot \mathrm{L}^{-1}\right)$ concentration. Results clearly demonstrated that chitosans were effective growth inhibitors of $P$. aeruginosa.

In the case of $P$. oleovorans, both $\mathrm{CS}_{\mathrm{L}}$ and $\mathrm{CS}_{\mathrm{H}}$ exhibited a similar rate of antimicrobial activity at all tested concentrations with the maximum inhibition also obtained at $5 \mathrm{~g} \cdot \mathrm{L}^{-1}$ concentration (Table 1). There was no significant difference in the inhibition of $P$. aeruginosa and $P$. oleovorans and this could be due to the reason that both species belonged to the same genus. Based on results, it could be concluded that $5 \mathrm{~g} \cdot \mathrm{L}^{-1}$ of chitosan was an effective concentration for achieving high level of antimicrobial activity against $P$. aeruginosa and $P$. oleovorans.

Despite that several different mechanisms for microbial inhibition by chitosan have been proposed, the exact mechanism is still unknown. The most accepted one is the interaction of the positively charged chitosan with the negatively charged residues at the cell surface of many fungi and bacteria, causing extensive cell surface alterations and altering cell permeability. This interaction would probably result in the leakage of intracellular substances (such as electrolytes, UVabsorbing material, proteins, amino acids, glucose, and lactate dehydrogenase) and thereby inhibiting the normal metabolism of microorganisms and finally leading to the death of these cells (Lim et al. 2003).

\section{Antimicrobial activity of the complexes of poly(acrylic acid)-chitosan}

Following the same methodology used for chitosan, the complexes NPEC1 and NPEC2 were tested at the $0.5 \mathrm{~g} \cdot \mathrm{L}^{-1}$ concentration. The results showed that NPEC1 complex inhibited $P$. oleovorans more effectively (32\%) than $P$. aeruginosa (22\%) (Fig. 2). At the same concentration, $P$. oleovorans and $P$. aeruginosa were inhibited only by $18 \%$ and $21 \%$, respectively by $\mathrm{CS}_{\mathrm{L}}$ and $\mathrm{CS}_{\mathrm{H}}$ (Fig. 2). The NPEC2 complex showed a superior inhibition against both $P$. aeruginosa and $P$. oleovorans. The different behavior of the complexes could be due to their composition specifically, availability of free carboxylic groups that could interact with bacterial cell wall. 


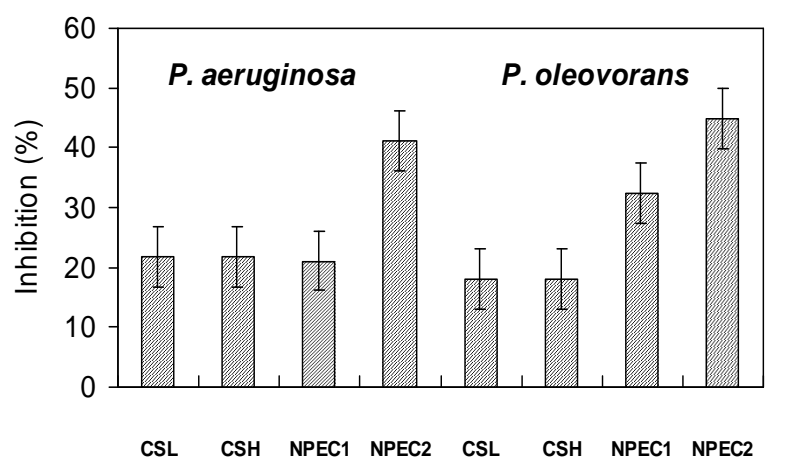

Figure 2 - Inhibition of $P$. aeruginosa and $P$. oleovorans in the presence of chitosan $\mathrm{CS}_{\mathrm{L}}$ and $\mathrm{CS}_{\mathrm{H}}$ and NPEC1 and NPEC2 complexes at a concentration of $0.5 \mathrm{~g} \cdot \mathrm{L}^{-1} ; \mathrm{pH} 4.5$.

Yang et al. (2003) reported that the inhibition of $P$. aeruginosa in polypropylene fabrics impregnated with chitosan at different concentrations (molecular weight was not reported) increased in relation to the increase in polypropylene/chitosan. The authors explained that chitosan being a cationic polysaccharide, the charge density of the fabric containing chitosan increased and improved the absorption of cells which were negatively charged, thereby decreasing the viable cell count. In solutions that contained only chitosan or complexes, there was no growth of any bacterial strains. Similarly, the total sugars were not detected in assays, which indicated that both the species of Pseudomonas did not have chitinases or chitosanases to break or degrade chitosan.

\section{CONCLUSIONS}

$P$. aeruginosa and $P$. oleovorans were effectively inhibited by both 65,000 and 325,000 molecular weight chitosans at the concentration of $5 \mathrm{~g} \cdot \mathrm{L}^{-1}$. The interpolyelectrolyte complexes of poly(acrylic acid)-chitosan, NPEC1 and NPEC2 showed a significantly higher inhibitory effect on $P$. oleovorans than $\mathrm{CS}_{\mathrm{H}}$ and $\mathrm{CS}_{\mathrm{L}}$ chitosans at $0.5 \mathrm{~g} \cdot \mathrm{L}^{-1}$ concentration. NPEC2 was most effective against both bacterial species than chitosans.

\section{RESUMO}

A atividade antimicrobiana de quitosana e complexos interpolieletrolíticos hidrossoluvéis de poli(ácido acrílico)-quitosana foi estudada.
Quitosanas de dois diferentes pesos moleculares foram testados em diferentes concentrações, $0,5 \mathrm{a}$ $5 \mathrm{~g} \cdot \mathrm{L}^{-1}$, como agentes antimicrobianos nas $P$. aeruginosa e $P$. oleovorans. Em ambos os casos, obteu-se a melhor inibição microbiana com a concentração de $5 \mathrm{~g} \cdot \mathrm{L}^{-1}$, no entanto os complexos interpolieletrolíticos de poli (ácido acrílico)quitosana com composição $\varphi=2$ apresentaram maior atividade antibacteriana do que os dois quitosans na concentração de $0,5 \mathrm{~g} \cdot \mathrm{L}^{-1}$. O complexo NPEC2 foi mais eficaz do que as quitosanas, sendo que o resultado pode ser atribuído ao número de moles dos grupos aminos da quitosana e aos grupos carboxílicos dos complexos de poli(ácido acrílico).

\section{REFERENCES}

Brandrup J. and Immergut, E. H. (1989), ViscosityMolecular Weight Relationships. In Polymer Handbook, Third Edition by John Wiley and Sons, Inc. New York, pp. VII/8.

Brugnerotto, J.; Lizardi, J.; Goycoolea, F. M.; Argüelles-Monal, W.; Desbriètes, J.; Rinaudo, M. (2001), An infrared investigation in relation with chitin and chitosan characterization, Polymer 42, 3569.

Costerton, J. W. (1980), Pseudomonas aeruginosa in nature and disease, Hans Huber Publishers, Bern, Switzerland, pp. 15-24.

Choi, G. J.; Kim, H. S.; Sim, S. J.; Kim, Y. D.; Woo, K. J.; Cho, Y. S. (1999), J. Chitin Chitosan 4, 90.

Chung, Y. C.; Wang, H. L.; Chen, Y. M.; Li, S. L. (2003), Effect of abiotic factors on the antibacterial activity of chitosan against waterborne pathogens, Bioresourse Technology, 88, 179-184. 
D’Argenio, D. A.; Gallegher, L. A.; Berg, C. A.; Manoil, C. (2002), Drosophila as a model host for Pseudomonas aeruginosa infection, J. Bacteriol., 183, 1466-1471.

Hardalo, C.; Edberg, S. C. (1997), Pseudomonas aeruginosa: Assessment of risk from drinking water, Crit. Microbiol., 23, 47-75.

Hirano, S.; Nagao, Y. N. (1989), Effect of chitosan, pectic acid, lysosyme and chitinase on the growth of several phytopathogens, Agric. Biol. Chem., 53, 3065-3066.

Hadwiger, L. A. "Chitosan: natural regulator in plantfungal pathogen interaction increases crop yields", Academic Press: San Diego 1984, p. 4.

Hidalgo, L.; Argüelles, W.; Peniche, C. (1989), Efecto de la quitosana en tratamientos a la semilla de tomate, Protección Vegetal., 11(1), 33.

Kabanov, V. A.; Zezin, A. V. (1984), Soluble Interpolymeric Complex as a New Class of Synthetic Polylectrolytes, Pure and Appl. Chem., 56(3), 343354.

Kang De Yao; Tao Peng; Goosen, M. F. A.; Ji Mei Min; Yu Yin He (1993), pH-sensitivity of hydrogels based on complex forming chitosan: Polyether interpenetrating polymer network, J. Appl. Polym. Sci,. 48, 343.

Lim, S. H.; Hudson, S. M. (2003), Review of chitosan and Its Derivatives as Antimicrobial Agents and Their Uses as Textile chemicals, J. Macromol. Sci., C43(2), 223-269.

Nelson, N. (1944), A photometric adaptation of the Somogyi method for determination of glucose. $J$. Biol. Chem., 153, 376-380.

Omura, Y.; Shigemoto, M.; Akiyama, T.; Saimoto, H.; Shigemasa, Y.; Nakamura, I.; Tsuchido, T. (2002), Reexamination of antimicrobial activity of chitosan having different degrees of acetylation and molecular weights, Advances in Chitin Sci., 6, 273-274.

Ortega-Ortiz, H.; Benavides-Mendoza, A.; FloresOlivas, A.; Ledezma-Pérez, A. (2003), Use of the Interpolyelectrolyte Complexes of Poly(acrylic acid)Chitosan as Inductors of Tolerance Against
Pathogenic Fungi in Tomato (Lycopersicon esculentum Mill. Var. Floradade), Macromol. Biosci., 3, 566-570.

Pace, N. R. (1997). A molecular view of microbial diversity and the biosphere. Science, 276, 734-740.

Peterson, G. L. (1977), Anal. Biochem. 83, 346-356.

Rahme, L. G.; Le, M. W. L.; Wong, S. M.; Tompkins, R. G.; Calderwood, S. B.; Ausubel, F. M. (1997), Use of model plant hosts to identify Pseudomonas aeruginosa virulence factors, Proc. Natl. Acad. Sci., 94, 13245-13250.

Rinaudo, M.; Milas, M.; Le Dung, P. (1993), Characterization of chitosan. Influence of ionic strength and degree of acetylation on chain expansion. Int. J. Biol., Macromol., 15, 291.

Shin, Y.; Yoo, D. I.; Jang, J. (2001), Molecular weight effect on antimicrobial activity of chitosan treated cotton fabrics, J. Appl. Polym. Sci., 80, 2495-2501.

Somogyi, N. (1952), Notes on sugar determination. Journal Biological Chemistry, 195, 19-23.

Tan, M. W.; Ausubel, F. M. (2000), Caenorabditis elegans: a model genetic host to study Pseudomonas aeruginosa patogenesis, Curr. Opin. Microbiol., 3, 29-34.

Xiao Fei Liu, Yun Lin Guang, Dong Zhi Yang, Zhi Li, Kang De Yao (2001), Antibacterial Action of chitosan and Carboxymethylated chitosan, J. Appl. Polym. Sci., 79, 1324-1335.

Yang, M. Y.; Lin, H. T.; Wu, T. H.; Chen, C. C. (2003), Wettability and Antibacterial Assessment of Chitosan Containing Radiation-Induced Graft Nonwoven Fabric of Polypropylene-g-Acrylic Acid, J. Appl. Polym. Sci., 90(5), 1331-1336.

Received: September 26, 2008; Revised: March 17, 2008; Accepted: May 19, 2009. 